\title{
Identification of the Factors Affecting the Academic Performance of the Science Undergraduates of the Eastern University, Sri Lanka: A Case Study
}

\author{
P. J. N. Thayamathy, P. Elango* \\ Department of Mathematics, Faculty of Science, Eastern University Sri Lanka, Sri Lanka
}

\begin{abstract}
Academic performance of Undergraduates in Sri Lankan Universities becomes an important factor among the academics and educators because the employability of the Sri Lankan graduate is growing as a challenge these days. Therefore, there is a need to identify and address the factors affecting the academic performance of Undergraduates in Sri Lankan universities. A survey designed was employed with questionnaires administered to the third year undergraduates of the Faculty of Science, Eastern University, Sri Lanka. The questionnaire covered the socio-economic factors, academic performances of the General Certificate of Education (GCE) Examinations in schools, extra studies of computer courses and English, extra-curricular activities and family backgrounds. The Grade Point Average for the first and second year of studies was used as the responses for the academic performance. The study revealed that gender, mother language, academic grades obtained for English language and general English at the GCE examinations, the stream of study of the degree programme in the University, the number of attempt at the GCE examination to enter the university were the mostly influencing factors. This study therefore recommended giving priority for learning mother language and improving English language and general English in GCE examinations in order to improve the academic performance of the students in the Faculty of Science, Eastern University, Sri Lanka.
\end{abstract}

Keywords: Academic Performance, Undergraduates, GPA, Gender, Proficiency in English.

DOI: $10.7176 / \mathrm{JEP} / 11-15-17$

Publication date:May $31^{\text {st }} 2020$

\section{Introduction}

Higher education is an important factor for the development of a country. Universities take a significant role to produce highly qualified graduates who become the source of manpower for the development of a country's economy.

Nowadays, academics and educators pay more attention on the student's academic performance in universities. Normally, academic performance is the basic tool for the recruitment by the employers. Therefore, students should achieve good performance to attain the employer's needs.

Sri Lankan education structure is divided into five levels: primary, junior secondary, senior secondary, collegiate and tertiary. Sri Lankan government offer free education for all levels of education including the university education. Sri Lanka has fifteen universities which are public institutions.

The admissions to these public universities are solely based on the results of the "General Certificate of Education (GCE) Advanced Level (A/L) examination". The students should study for two years at collegiate level before taking this examination. The examination diversifies over five major fields of studies such as physical science, biological science, commerce, arts, and technology streams. In each stream, students should offer three main subjects. Furthermore, there would be a general English test and a common general test. The result of the general English test is not taken into account for the university entrance selection criteria but students are expected to obtain a pass mark for the common general test. Based on the GCE (A/L) examination results, the University Grants Commission (UGC) prepares a list of Z-scores for university admission.

Succeeding the enrolment to the science undergraduate degree programs to the universities, students face a new academic environment where all the academic activities such as lecturers, practical sessions, presentations and seminars are conducted in English medium. But in school level, mostly the medium of the instructions is their mother tongue which is either Tamil or Sinhala language whereas, English is teach as the second language.

\section{Material and methods}

\subsection{Objective of Study}

The objective of this study is to identify the factors affecting the academic performance of the Undergraduate of the academic year 2013/2014 of the Faculty of Science, Eastern University, Sri Lanka. The secondary objective of this research is to define the common factors which would be the affecting factors of the academic performance of the Undergraduate of the Faculty of Science in Eastern University, Sri Lanka. 


\subsection{Literature Review}

There are several researches have been conducted to identify and analyze the factors affecting the academic performance of undergraduates in Universities. In identifying the factors affecting the quality of academic success, a broad list of factors that have been used as predictors of academic performance, including collegiate academic performance, attendance, age, gender, ethnicity and so on.

A study conducted by Anderson and Benjamine (1994) showed that student's effort, previous schooling was significantly related to the student's outcomes. There were some studies carried out to explore the relationship between student attendance and exam performance; Romer (1993), Newman- Ford et al. (2009) have pointed out that the major reasons given by students for poor attendance were assessment pressures, timing of lectures, poor delivery of lectures and working commitments.

Indeed, web-based learning approaches have become the order of the day. The development of these facilities that either make it impossible or unnecessary for students to attend classes, at this point, there was a question raised that how the absenteeism affect the student's academic performance? Schmidt (1983), Park and Kerr (1990), Durden and Ellis (1995), Devadoss and Folt (1996) made studies on whether the absenteeism affects student's academic performance. The study seems to provide a consensus that students who attend classes perform highly compared to those who missed the classes.

Durden and Ellis (1995) identified a nonlinear effect of attendance on learning that means, a few absences did not lead to poor performance but excessive absenteeism. Harb and El-shaarawi (2007) found the factors that affecting the student's achievements. The study was made at college of Business and Economics in United Arab Emirates. The results of the study revealed that the missing many lecturers and living in a crowded household negatively affected students' performance. In Srinakharinwirot university in Thailand, Sattaayanuwat (2015) conducted a research to identify the factors affecting student's performance. The study indicated that the attendance of the lectures and tutorial classes directed to improve the good performance and also the performance of male students were better than the female counter part.

Pinyopornpanish et al. (2004) conducted a research to find the factors that mostly involved on the students' performance. From his study, he identified that there were three groups of factors associated with low academic achievement. The first factor was related to the students themselves. They included frequent absence from classes, male, old age students, mental illness, lack of academic motivation in studying medicine and personality disorders. The second factor was related to the university environment and consisted of numerous extra-curricular activities, bad attitude towards the course, and relationships with and adjustment to teachers and friends. The last factor was associated with the students' family and consisted of attitude toward up-bringing such as overprotection and over control. This study identified that the performance of female student was better than the male students.

Another characteristic recognized as a major factor that affect the tertiary success was student's level of wealth or socio-economic standing. Most researches showed a positive association between student's wealth and their tertiary grades. There was a positive relationship between the student's success and socio-economic or wealth was reported by Robert and Keil (2000). Some studies said that the parent's supports and types of parenting also involved on the variance in student's performance. Eweniyi (2002), Okolie et al. (2014), Akessa and Dhufera (2015) investigated some factors that affect the student's performance. The research was done at Rift Valley universities in Ethiopia. They found an important relationship between the academic achievements and their parent's education level. The economic status of their families also influenced on their performance.

The student enrolment qualifications are differing from institute to institute, country to country and course to course. In University of Western Australia, Win and Miller (2005) conducted a research and identified the factors that affect the student's performance. The main conclusion was drawn from the research was that the secondary education institutions or schools had a large impact on the performance of undergraduate students rather compare with the individual factors and identified the educational level of the parents also influenced on the student's performance.

Some institutional factors were investigated by Osaikhiuwa (2014) such as unfavorable learning environment, inadequate water supply and insufficient library facilities but there were not any relationships between these factors and student's performances but some other factors were identified such as overcrowded lectures room, breakdowns of electricity supply, continuous strikes and closure of school had a significant impact on student's performance.

Everett and Robins (1991); Abbott-chapman et al. (1997); Win and Miller (2005); suggested that female students obtained better performance than their male counterparts. Contrary to this Myatt and Waddell (1990); Mandal et al. (2012) reported that male students obtained better performance than their female students. On the other hand, Durden and Ellis (1995); Borde (1998); Marcal and Roberts (2001); O'Malley and Stranahan (2002) reported from their research findings that there was no evidence that gender influence on the performance of students.

A student's age may also affect the scholastic achievements at universities. Many researches were carried out. Ruegger and King (1992) indicated that the older students had higher performance than the younger students in 
business courses at the University of Southern Mississippi.

Mandal et al. (2012) identified the factors such as gender, inability to clear the previous professional examination at the first attempt, difficulty in understanding medium of instruction, self-assessed depression, sleep disorders, perceived parental and peer pressure and dissatisfaction with career choice were significantly linked with poor performance. Socioeconomic status and regularity in class were not linked to academic performance. In summary, there is a wide range of factors associated with the student's performance in universities.

\subsection{Methodology}

The aim of this study was to identify the factors which affect the academic performance of the Undergraduate in the Faculty of Science, Eastern University, Sri Lanka. For this study, the third year students from the academic years 2013/2014 were considered since only the third year students have the results for the first and second year of studies which was needed for the GPA calculation. The total number of bio-science students and the physical science students were 47 and 65 respectively in this third year batch. The objective of this study was clearly explained to the students and the confidentiality of the data was assured to them. Then the respondents were selected by using random sampling for both biological and physical science students by using the statistical package Minitab. A total of 80 questionnaires were administrated for the third year students. Among these questionnaires, a total of 76 were filled and returned which represented $67.9 \%$ of the total students in the third year. Among the 76 responses, 35 responses were from the biological students and 41 responses were from the physical science students.

Based on the authors' previous similar study (2018) and factors from the literature review, the questionnaire was designed. The first section of the questionnaire was administrated to collect information about gender, district of living, fluency in mother language and the fluency in the second language English in GCE $(\mathrm{O} / \mathrm{L})$ and general English in GCE (A/L) examinations.

The second section of the questionnaire contained the details of school education such as performance of the grade 5 scholarship, name of the school, district and the year in which they sat for the GCE $(\mathrm{O} / \mathrm{L})$ examination, results of the four main subjects (Mathematics, Science, English, and the mother language) in GCE (O/L) examination, the information about GCE (A/L) examination such as the stream of study, medium of study, the number of attempt(s) they sat to enter the university, z-score in which they entered the university and the grade of general English.

The third section of the questionnaire contained the information of the university studies such as the subject combination, type of degree (general/special) and the current year of studies. The fourth section contained the information about the additional learning: whether they followed English, and computer courses before entering the university and the information of other courses currently following parallel to the university degree programme.

The fifth section about the family background: bread winner's occupation and the information about any degree holders in their immediate family. The last section requested the information about the extracurricular activities such as sports, being a member of the societies, music band, social services and the research activities.

All the data of independent variables were collected through the questionnaires. The study used the academic performance as a dependent variable. The academic performance measured based on GPA. With the permission of the Faculty, GPA was collected from the office of the Dean Science. The questionnaires were checked for completeness and consistency before entering the data and analyzed. The descriptive statistical techniques such as frequency distribution and percentages were used to analyze the data. ANOVA test and simple regression analysis were established and explained the relationship between the independent variables (factors) and the academic performance (GPA).

\section{Results and discussion}

For this study, a random sample of 76 students from the batch of academic year 2013/2014 was asked to fill the questionnaire. It is noted that the majority of students $(65.8 \%)$ are female students while the remaining $(34.2 \%)$ are male students.

Since the medium of instruction of the Faculty of Science is English, the students are asked to response their English language proficiency by evaluating them-self (self-evaluation method). The following table shows the response of their English language proficiency:

Table 1: Fluency in English language

\begin{tabular}{|l|c|c|c|}
\hline \multirow{2}{*}{ English Component } & \multicolumn{3}{|c|}{ Performance } \\
\cline { 2 - 4 } & Good & Moderate & 3.9 \\
\hline Speaking & 38.2 & 57.9 & 1.3 \\
\hline Reading and writing & 64.5 & 34.2 & Poor \\
\hline
\end{tabular}

According to the self-evaluation responses of the students, it is noted that most of the students are in good level in reading and writing skills while most of them are in moderate level in speaking skills.

The grade 5 scholarship examination is the first competitive examination for school students and give 
opportunities for admissions to the best schools to the senior secondary schools. The data shows that about $60.5 \%$ of undergraduate of the Faculty of Science passed their grade 5 scholarship examinations. Since the students can sit the $\operatorname{GCE}(\mathrm{A} / \mathrm{L})$ examination for three times for University entrance, it is found that about $56.6 \%$ of students entered to University at their 2 nd attempt while about $30.3 \%$ of students entered the University at their 1 st attempt. The remaining students (13.2\%) entered the University at their 3rd (last) attempt. It is also found that about $55.3 \%$ of students did not follow any computer courses during their school period. But after the GCE (A/L) examinations, about $61.8 \%$ of students followed some computer courses. It is also found that about $60.5 \%$ of students followed some English courses after the GCE (A/L) examinations. The students' responses also show that nearly $14.5 \%$ of them are following some job oriented courses parallel to their undergraduate degree programs.

According the sample data, it is found that about $52.6 \%$ of students are participating the sports activities during their University studies and about $36.8 \%$ of student are being a member in a student society in the University. But a low percentage of students are interested in playing musical bands. It is also found that the students' involvement in social activities is higher $(56.6 \%)$ than their involvement in research activities $(14.5 \%)$. The data also shows that about $31.6 \%$ of students are having a degree holder in their immediate family.

From our research it is found that there are ten factors which are influencing the academic performance of the undergraduates of the Faculty of Science. Among these ten factors, the following six factors are mostly influencing the academic performance which are the gender, mother language, grade obtained for English language at the GCE $(\mathrm{O} / \mathrm{L})$ examination, grade obtained for general English at the GCE $(\mathrm{A} / \mathrm{L})$ examination, the stream of study of the degree programme in the University, the number of attempt at the GCE $(\mathrm{A} / \mathrm{L})$ examination to enter the university. The remaining four factors which are the medium of the study of the GCE $(\mathrm{A} / \mathrm{L})$ subjects, following other courses parallel to the degree program, being member(s) in the society/societies, and the involvement in social activities are moderately influencing the academic performance of the students. These are identified according the results of ANOVA test. The p-values of these factors are given in the Tables 2 and Table 3 below. The p-values of some factors are much smaller than the significant level 0.05 ; this indicates that academic performance is highly depending on those factors.

Table 2: Factors related to student's GPA

\begin{tabular}{|c|c|c|c|}
\hline Factor & Levels of factor & $\begin{array}{l}\text { Estimates mean GPA for each } \\
\text { level }\end{array}$ & $\begin{array}{c}\text { P- } \\
\text { value }\end{array}$ \\
\hline \multirow[t]{2}{*}{ Gender } & Male & 2.2901154 & \multirow{2}{*}{0.000} \\
\hline & Female & 3.0296340 & \\
\hline \multirow[t]{2}{*}{ Mother language } & Tamil & 3.0812091 & \multirow{2}{*}{0.005} \\
\hline & Sinhala & 2.6525574 & \\
\hline \multirow[t]{5}{*}{ Grade for English language at GCE $(\mathrm{O} / \mathrm{L})$} & Grade A & 2.9396070 & \multirow{5}{*}{0.002} \\
\hline & Grade B & 2.8129786 & \\
\hline & Grade C & 2.5519231 & \\
\hline & Grade $\mathrm{S}$ & 2.1463200 & \\
\hline & Grade F & 1.3333000 & \\
\hline \multirow[t]{5}{*}{ Grade for general English at GCE (A/L) } & Grade A & 3.1923400 & \multirow{5}{*}{0.001} \\
\hline & Grade B & 2.5130091 & \\
\hline & Grade C & 2.9494150 & \\
\hline & Grade $\mathrm{S}$ & 2.8747500 & \\
\hline & Grade F & 2.3316600 & \\
\hline \multirow[t]{2}{*}{$\begin{array}{l}\text { Stream of study of the degree programme in } \\
\text { University }\end{array}$} & $\begin{array}{l}\text { Biological } \\
\text { science }\end{array}$ & 3.0755743 & \multirow[t]{2}{*}{0.000} \\
\hline & Physical science & 2.5214537 & \\
\hline \multirow{3}{*}{$\begin{array}{l}\text { Number of attempts in GCE (A/L) to enter to } \\
\text { University }\end{array}$} & $1 \mathrm{st}$ & 3.0944870 & \multirow{3}{*}{0.002} \\
\hline & $2 \mathrm{nd}$ & 2.7011977 & \\
\hline & $3 r d$ & 2.3700000 & \\
\hline \multirow[t]{3}{*}{ Medium of studies of the GCE (A/L) subjects } & Tamil & 3.0812091 & \multirow{3}{*}{0.010} \\
\hline & Sinhala & 2.6278620 & \\
\hline & English & 2.9612500 & \\
\hline \multirow{2}{*}{$\begin{array}{l}\text { Following other courses parallel to degree } \\
\text { programme }\end{array}$} & Yes & 2.3671091 & \multirow{2}{*}{0.015} \\
\hline & No & 2.8459462 & \\
\hline \multirow[t]{2}{*}{ Being member (s) in the society/societies } & Yes & 2.5642786 & \multirow{2}{*}{0.019} \\
\hline & No & 2.9005187 & \\
\hline \multirow[t]{2}{*}{ Involvement in social activities } & Yes & 2.6557279 & \multirow{2}{*}{0.047} \\
\hline & No & 2.9341939 & \\
\hline
\end{tabular}

This study measures the factor "gender" which is positively related to the academic performance of the 
students. It is found that the GPA of the female students is higher than that of male students and differs on average of about 0.74 . From the result shown in Table 2 above, we also find that the mother language of the students is also positively related to the GPA of the students. The performance of the English language at the GCE $(\mathrm{O} / \mathrm{L})$ and general English at the GCE (A/L) examinations have significant effect on the student's GPA. In order to identify the important factors which influence the academic performance of students, the fitted regression model is given as

$$
\mathrm{GPA}=2.099+1.082 \mathrm{Z} \text { - score }
$$

with the predictor Z- score at GCE $(\mathrm{A} / \mathrm{L})$ examination. Here the regression coefficient and intercept are significant. Regression coefficient in the regression equation is 1.082 . This coefficient represents the mean increase of GPA for every additional one unit change in Z-score. If the Z-core increase by one unit, the average GPA increase by 1.082 .

In addition to the above mentioned ten factors which are influencing the academic performance of students, the following factors are found to be the non-affecting factors of the academic performance of the students: the district of residency of the students, English speaking ability, English reading ability, Pass/Fail of the grade 5 scholarship examination, performances in their mother language at the GCE $(\mathrm{O} / \mathrm{L})$ examination, performance of the Mathematics and Science subjects at the GCE (O/L) examination, learnt computer courses at the school, followed English and computer courses after the GCE (A/L) examination, extracurricular activities (involving sports activities, playing in musical band) and involvement in research activities in the university during their degree programmes and the status of having a graduate at their home.

Table 3: Factors that do not affect GPA

\begin{tabular}{|l|l|}
\hline \multicolumn{1}{|c|}{ Factor } & \multicolumn{1}{|c|}{ P-value } \\
\hline District of residency & 0.732 \\
\hline English speaking ability & 0.189 \\
\hline English reading ability & 0.245 \\
\hline Grade 5 scholarship examination results (pass/fail) & 0.389 \\
\hline GCE (O/L) examination grade on the subject of Mother language & 0.197 \\
\hline GCE (O/L) examination grade on the subject of Science & 0.375 \\
\hline GCE (O/L) examination grade on the subject of Mathematics & 0.136 \\
\hline Learnt computer courses at the school & 0.071 \\
\hline Followed English courses after the GCE (A/L) examination & 0.152 \\
\hline Followed Computer courses after the GCE (A/L) examination & 0.116 \\
\hline Involving sports activities & 0.301 \\
\hline Playing in musical band & 0.813 \\
\hline Involvement in research activities & 0.638 \\
\hline Having a degree holders at the home & 0.272 \\
\hline
\end{tabular}

In our previous study (2018) conducted for the undergraduates of the academic year 2012/2013 (directly previous batch) of this Faculty, it is found that the influencing factors are almost same in both studies. The previous study revealed that except the factor "the number of attempts in CGE (A/L) examination to enter the University", all other factors were identified as the most significant factors which affect the academic performance of the students of the academic years 2012/2013.

It is also found that the four factors such as such the medium of the study of the GCE (A/L) subjects, following other courses parallel to the degree program, being member(s) in the society/societies, and the involvement in social activities which are moderately influencing the academic performance of the students of the academic year 2013/2014 were not significant for the previous batch (2012/2013) of students. All other factors listed in the Table 3 are not significant for both batches of students.

Some of the earlier studies consistence with our findings: Win and Miller (2005), Everett and Robins (1991), Abbott-chapman J, Gary E, O' Connor P (1997), Mandal et al. (2012) suggested that the gender is a significant factor of the students' performance and also found that female students" performance was better than the male students' performance. Mandal et al. (2012) found that the difficulty in understanding medium of instruction had significantly linked with the poor performance of students which is also a significant factor of the students' performance in this study. Also Harb Nasri and El-Shaarawi Ahmed (2007) stated that the most important factor that affects student's performance is the student's competence in English.

\section{Conclusion}

Gender, mother language, performances of the English language at the GCE $(\mathrm{O} / \mathrm{L})$ examination and the general English at the GCE $(\mathrm{A} / \mathrm{L})$ examination, the stream of study of the degree programme in the University are the most influencing factors which affect the academic performance of the undergraduates of the Faculty of Science, Eastern University, Sri Lanka. This is identified by two separate studies on the undergraduates of the academic years 
2012/2013 and 2013/2014 of the Science undergraduates of this Faculty. The p-values of these factors are much smaller than the significant level 0.05 . In this study, it is also found that the number of attempts at the GCE (A/L) examination to enter the university became another significant factor that affects the academic performance of the undergraduate of the academic years 2013/2014.

The medium of the study of the GCE (A/L) subjects, following other courses parallel to the degree program, being member(s) in the society/societies, and the involvement in social activities are moderately influencing the academic performance of the students of the academic year 2013/2014 but not significant for the previous batch $(2012 / 2013)$ of students.

In both studies, it is found that the district of residency of the students, English speaking ability, English reading ability, pass/fail of the grade 5 scholarship examination, performance in their mother language at the GCE $(\mathrm{O} / \mathrm{L})$ examination, performance of the Mathematics and Science subjects at the GCE $(\mathrm{O} / \mathrm{L})$ examination, learnt computer courses at the school, followed English and computer courses after the GCE (A/L) examination, extracurricular activities (involving sports activities, playing in musical band), involvement in research activities in the university during their degree programmes and the status of having a graduate at their home are not affecting the academic performance of both batch of students are the non-affecting factors of the academic performance of the students.

Based on these two studies, it is recommended to give priority for learning mother language and improving English language in GCE $(\mathrm{O} / \mathrm{L})$ and general English in GCE $(\mathrm{A} / \mathrm{L})$ in order to improve the academic performance of the students in the Faculty of Science, Eastern University, Sri Lanka.

\section{References}

Abbott-chapman, J., Gary, E., O’Connor, P. (1997). The influence of student gender and parental socio-economic status on postschool career paths. The Australian Journal of Social Research, (1):3-26.

Akessa, G., M., and Dhufera, A., G. (2015). Factors that influences students' academic performance: A case of rift valley University, Jimma, Ethiopia. Journal of Education and Practice, 6(22):55-63.

Anderson, G., and Benjamin, D. (1994) The determinants of success in university introductory economics courses. J Econ Educ., 25(2):99-119.

Borde, S., F. (1998). Predictors of student academic performance in the introductory marketing course. Journal of Education for Business, (5):302-307.

Devadoss, S., and Foltz, J. (1996). Evaluation of factors influencing student's attendance and performance. Am J Agric Econ, 499-507.

Durden, G., C., and Ellis, L., V. (1995). The effects of attendance on student learning in principles of economics. Am Econ Rev, 85(2):343-346.

Everett, J., E., and Robins, J. (1991). Tertiary entrance predictors of first-year university Performance, Aus J Educ., 35(1):24-40

Eweniyi, G., D. (2002). The impact of family structure on university students' academic performance. Olabisi Onabamijo University, ago-lwoye.

Harb, N. and El-Shaarawi, A. (2007). Factors Affecting Students' Performance. Journal of Business Education, 82(5): 282-290.

Mandal, A., Ghosh, A., Sengupta, G., Bera, T., Das, N., Mukherjee, S. (2012). Factors affecting the performance of undergraduate medical students: A perspective. Indian Journal of Community Medicine, 37(2):126-129.

Marcal, L., Roberts, W., W. (2001). Business statistics requirements and student performance in financial management. Journal of Financial Education, 27:29-35.

Myatt, A., and Waddell, C. (1990). An approach to testing the effectiveness of the teaching and learning of economics in high school. Journal of Economic Education. 21:355-363.

Newman-Ford, L., Lloyd, S., Thomas, S. (2009). An investigation in the effects of gender, prior academic achievement, place of residence, age and attendance on first year undergraduate attainment. Journal of Applied Research in Higher Education, 2009;(1):13-28.

Okolie, U., C., Inyiagu, E., E., Elom, E., N., Ndem, J., U., Nwuzo, A., C. (2014). Effect of home back ground on academic performance of technical college students in Ebonyi State, Nigeria. The International Journal of Humnities and Social Studies, 2(5):76-82.

O'Malley, B., and Stranahan, H. (2002). The effect of gender and race on student performance in principles of economics: The importance of personality type. J Appl Econ, 34(5):589-598.

Osaikhiuwu, O., C. (2014). Institutional factors affecting the academic performance of public administration students in a Nigerian University, Public Administration Research, 3(2):171-177.

Park, K., H., and Kerr, O., M. (1990). Determinants of academic performance: A multinomial logit approach. J Econ Educ, 21(2):101-111.

Pinyopornpanish, M., Sribanditmongkok, P., Boonyanaruthee, V., Chan-ob, T., Maneetorn, N., and Uuphanthasath, R. (2004). Factors affecting low academic achievement of medical students in the faculty of medicine, chiang 
Mai University. Chiang Mai Med Bull, 43(1):15-23.

Robst, J., and Keil, J. (2000). The relationship between athletic participation and academic performance: Evidence from NCAA Division III. J Appl Econ, 32(5):547-558.

Romer, D. (1993). Do students go to class? Should they? J Econ Perspect, 7(3):167-74.

Ruegger, D., and King, E., W. (1992). A Study of the Effect of Age and Gender upon Student Business Ethics. Journal of Business Ethics, 11: 179-186.

Sattayanuwat, W. 92015). Determinant of student performance in international trade course. Am J Educ Res, 3(11):1433-1437.

Schmidt, R. (1983). Who maximizes what? A study in student time allocation. Am Econ Rev, (Papers and Proceedings), 73(2):23-28.

Thayamathy, P., J., N., Elango, P., Karunarathna, K., A., N., K. (2018). Factors Affecting Academic Performances of Undergraduates: A Case Study with Third Year Science Undergraduate of Eastern University,Sri Lanka. Journal of Education, Society and Behavioural Science, 25(3): 1-10.

Win, R., and Miller, P. (2005). The effects of individual and school factors on university students' academic performance. Aus Econ Rev., 38(1):1-18. 